\title{
Synthesis of a 5-(Hydroxymethyl)furfural-based resin and its use as heterogeneuos catalyst.
}

\section{Lucas P. Fernandes*, Renan Galaverna, Gustavo R. Gomes and Julio C. Pastre.}

\section{Abstract}

The synthesis and characterization of a new 5-(Hydroxymethyl)furfural-based resin was evaluated. The product obtained, a dark brownish solid and insolluble in several organic solvents and water, presents acidic properties (- $\mathrm{COOH}$ ). The characterization was performed by using FTIR, solid carbon NMR, TGA, DSC analyses and the results showed an amorphous material. Its acidity was explored in an organic reaction under continuous flow conditions.

\section{Key words:}

Flow chemistry, Green chemistry, Heterogenous catalysis

\section{Introduction}

The use of renewable raw materials, such as biomassderived compounds, to the production of chemicals and materials has gained considerable attention aiming at the substitution of fossil-based compounds.

In this study, a polymeric material was obtained after an unsuccessful attempt to do a Diels-Alder reaction between 2,5-di(hydroxymethyl)furan (DHMF) and maleic anhydride. In view of the acidity presented by the synthesized compound, it was investigated as a heterogeneous catalyst for a known transformation, allowing its comparison to an acid sulphonic acid resin reported in the literature. ${ }^{1}$

\section{Results and Discussion}

Firstly, the diene (DHMF, 2) was prepared from 5-HMF and was used in the Diels-Alder reaction with maleic anhydride (3).

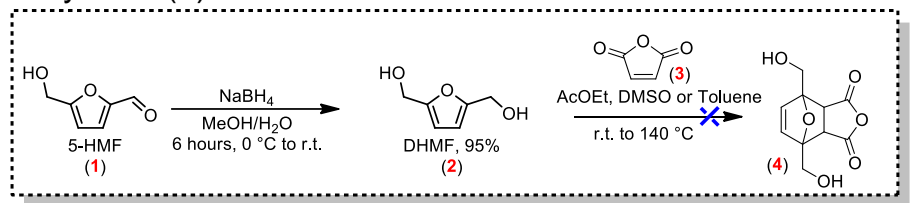

Scheme 1: DHMF synthesis and Diels-Alder reaction using maleic anhydride as dienophile.

The desired Diels-Alder adduct could not be isolated using several conditions (solvent and temperature screening). At $140{ }^{\circ} \mathrm{C}$, a dark brownish solid was formed after a few seconds of mixing and several analyses were performed in order to characterize this material. Scheme 2 shows part of the solid state ${ }^{13} \mathrm{C}$ NMR spectrum obtained and the carbon assignment.

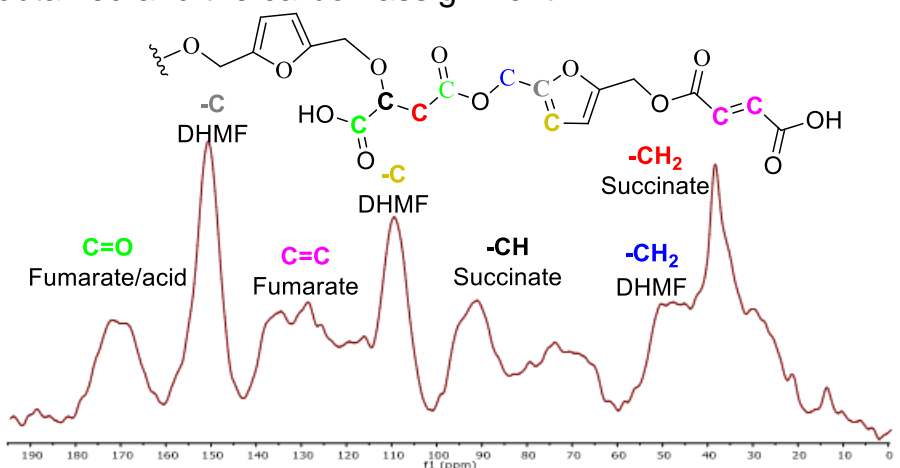

Scheme 2: Solid state ${ }^{13} \mathrm{C}$ NMR for the HMF-based resin.

According to the pattern observed, the mechanism that follows was proposed to explain the structure and the acidity of the synthetized solid.

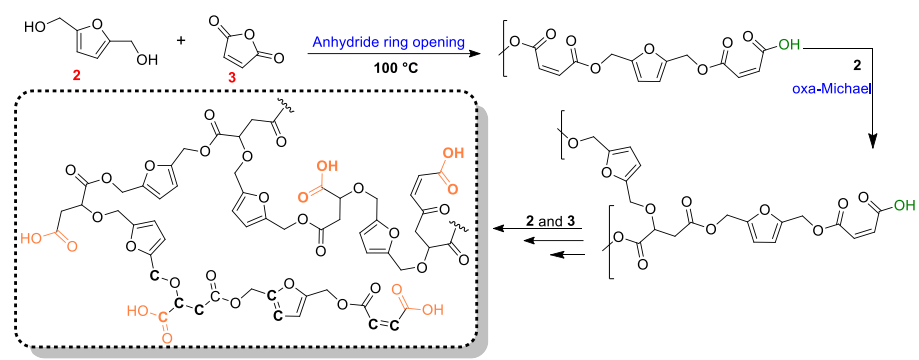

Scheme 3: Proposed mechanism for the resin formation.

After the structure was elucidated, the ionic change capacity was measured and defined as $1.7 \mathrm{mmol} . \mathrm{g}^{-1}$. Then, this acidic resin was evaluated as a heterogenous catalyst in the dehydration of fructose.

Table 1. Acid catalyzed dehydration of D-Fructose to 5HMF in continuous flow regime.

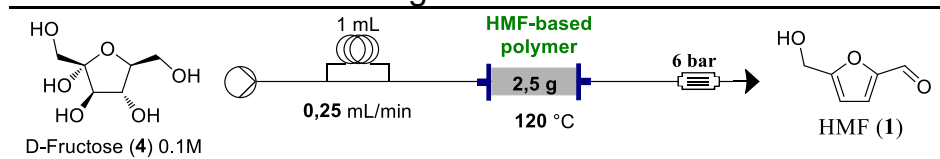

\begin{tabular}{ccccc}
\hline Entry ${ }^{[\mathrm{a}]}$ & $\mathbf{T}\left({ }^{\circ} \mathbf{C}\right)$ & $\begin{array}{c}\text { Flow rate } \\
\left(\mathbf{m L . m i n}^{-\mathbf{1}}\right)\end{array}$ & $\mathbf{P}$ (bar) & $\begin{array}{c}\text { Yield } \\
(\mathbf{\%})\end{array}$ \\
\hline $1^{[\mathrm{c}]}$ & 120 & 0.25 & 6 & 62 \\
2 & 120 & 0.25 & 6 & 50 \\
3 & 120 & 0.25 & 6 & 40 \\
$4[\mathrm{~d}]$ & 120 & 0.25 & 6 & 70 \\
5 & 120 & 0.25 & 6 & 40 \\
6 & 120 & 0.25 & 6 & 40 \\
7 & 120 & 0.25 & 6 & 40 \\
\hline
\end{tabular}

[a] Fructose in $\mathrm{DMSO} / i-\mathrm{PrOH}(15 \% \mathrm{v} / \mathrm{v})$ and only $i-\mathrm{PrOH}$ as solvent ${ }^{[b]}$ Yield was determined by using 1,3,5-trimethoxybenzene as internal standard for ${ }^{1} \mathrm{H}$ NMR. [c] First run after activation using $\mathrm{HCl} 1 \mathrm{M}$ in the 1 $\mathrm{mL}$ loop.[d] First run after a second reactivation using $\mathrm{HCl} 1 \mathrm{M}$.

\section{Conclusions}

The strategy adopted here allowed the characterization of the unexpected polymeric product. Its physicochemical properties were determined and an application for this material was presented. Although it leads to lower yields than those reported in the literature, the resin showed potential application as a heterogeneous catalyst.

Acknowledgement

The authors gratefully acknowledge financial support from FAPESP, CNPq, CAPES and FAEPEX.

1 R. Galaverna, M. C. Breitkreitz, J. C. Pastre, ACS Sustainable Chem Eng. 2018, 6, 4220-4230. 